\title{
A Socio-technical Analysis of Interdependent Infrastructures among the Built Environment, Energy, and Transportation Systems at the Navy Yard and the Philadelphia Metropolitan Region, USA
}

\author{
Darryl Farber and Martin T. Pietrucha \\ Engineering Systems Program, The Larson Institute, Penn State University, USA
}

\begin{abstract}
This paper reports on a research initiative that explores the interdependencies of the system of systems - the built environment, energy, and transportation - related to the redevelopment of The Navy Yard in Philadelphia and the Philadelphia Metropolitan Region. The overarching goal of the project is a clearer understanding of the dynamics of multi-scale interactions and interdependencies of systems of sociotechnical systems that will be useful to system practitioners. The understanding and the subsequent planning and design of sociotechnical systems are "wicked" problems and one characteristic is there is no definitive formulation. One of the main findings or lessons learned of the work reported for the understanding of interdependencies of infrastructure is the identification of what are the problems or challenges because for wicked problems "[t]he formulation of the problem is the problem!"

We find that systems practitioners have an overarching concern of a fragmented regional policy and decision making process. Four main themes of 1 . Vulnerability of aging infrastructure, 2. Integration of emerging technology into existing infrastructure, 3. Lifestyle and value changes, and 4. Financial innovations were identified as challenges. Continuing research work explores three possible infrastructure projects for further study as well as the development of a high-level systems of systems model. The principle outcome is the initiation of a planning process so that the system practitioners will learn to better understand the connections among related sociotechnical systems and the constellation of problems they face not within their immediate scope of responsibility yet influences the operations of their systems.
\end{abstract}

Keywords: Interdependent Infrastructure, Socio-Technical Systems Analysis, Scenario Planning, Risk Management, Strategic Investment

\section{INTRODUCTION}

This paper reports on a research initiative that explores the interdependencies of the system of systems - the built environment, energy, and transportation - related to the redevelopment of The Navy Yard in Philadelphia and the Philadelphia Metropolitan Region. The overarching goal of the project is a clearer understanding of the dynamics of multi-scale interactions and interdependencies of systems of sociotechnical systems that will be useful to system practitioners ${ }^{1}$. The understanding and the subsequent planning and design of sociotechnical systems are "wicked" problems and one characteristic is there is no definitive formulation². One of the main findings or lessons learned of

\footnotetext{
1 Rouse, W. \& Bodner, D.A. Multi-Level Modeling of Complex Socio-Technical Systems. Center for Complex Systems \& Enterprises. Report No. CCSE-2013-01 (2013).

2 Rittel, H. W. J. \& Webber, M. M. Dilemmas in a General Theory of Planning. Policy Sci. 4:155-169 (1972).
} 
the work reported for the understanding of interdependencies of infrastructure is the identification of what are the problems or challenges because for wicked problems "[t]he formulation of the problem is the problem"

A challenge is to understand why stakeholders may have different interpretations or "mental models" of how infrastructure sociotechnical systems function, even for supposedly the same systems, which is valuable knowledge for understanding "whole" systems of systems functioning. The knowledge generated then serves to inform the construction and evaluation of sociotechnical theory as well as to inform the practice of strategic infrastructure decision making and implementation in the public and private sectors. The initiative is reliant on collaboration with system practitioners in the development of models, simulations, and scenarios of the many system and component interactions. It is through collaboration with system practitioners that "an image of the problem and of the solution emerges gradually among the participants, as a product of incessant judgment, subject to critical argument" and is distinctly different from the conventional or "first generation" systems engineering approach².

The principle outcome of the analysis is not a static strategic plan. It is the initiation of a planning process so that the system practitioners will learn to better understand the connections among related sociotechnical systems and develop an expanded understanding of the constellation of problems they face that is not within their immediate scope of responsibility yet influences the operations of their systems. In engaging with systems practitioners and potentially influencing and engineering the sociotechnical systems, one faces the question about the validity and veracity of the knowledge generated ${ }^{3}$. In other words, how is systems knowledge considered scientific knowledge and why? What constitutes scientific knowledge of a system when one is intervening in the behavior of sociotechnical systems? "What is an application and when is theory a waste of time ${ }^{4}$ ?" How can the scientific knowledge be used to create systems innovations that will make the systems resilient, secure, environmentally responsible, economically competitive, and socially acceptable 5,6 ? On the one hand, to what extent is the design and evolution of sociotechnical infrastructure systems a "wicked" problem and as such, there are limits to what is scientifically knowable 2 ? On the other hand, are there concepts and methods that can represent and model a sociotechnical system of systems, including interventions, such that one may gain insight into the possible ways the systems may change over time ${ }^{7}$ ?

The increasing interdependencies of the systems generate many direct and even more indirect risks that are not well understood so that communication among the multiple stakeholders is essential to insure a fair and reasonable representation of perspectives. The aim is that systems practice drives the development of the research and theory to insure that the outcomes are management and policy relevant so that one needs a new way of thinking about and understanding the independencies of large-scale, complex, interdependent, infrastructure systems ${ }^{8}$. In the development of a new way to think through and formulate the problems, however, there are at least three types of errors one may make:

Type I Error: Detecting a problem when there isn't one.

Type II Error: Not detecting a problem when there is one.

Type III Error: Solving the wrong problem .

"Most research on decision making focuses on how problems are solved [. . . not] which problems are solved and how alternatives are generated for problem solving. These are fundamental activities underlying effective problem solving. Clearly, if we spend our time solving the wrong problems or if we restrict attention to an inferior set of alternative solutions, then no matter how effective our problem-solving procedures may be, the outcome will be

3 Oreskes, N., Shrader-Frechette, K. \& Belitz, K. 1996. Verification, Validation, and Confirmation of Numerical Models in the Earth Sciences. Science 263: 641-646.

4 Shubik, M. What is an Application and When is Theory a Waste of Time? Management Sci. 33: 1511-1522 (1987).

5 de Weck, Olivier, Roos, D. \& Magee, C.L. Engineering Systems: Meeting Human Needs in a Complex Technological World. Cambridge, MA: The MIT Press (2011).

6 Barami, B. Infrastructure Resiliency: A Risk-Based Framework. Excerpt of white paper. John A. Volpe National Transportation Systems Center, U.S. Department of Transportation (2013).

7 Batty, M. The New Science of Cities. Cambridge, Massachusetts: The MIT Press (2013).

8 Tran, M., Hall, J., Hickford, A., Nicholls, R., Alderson, D., Barr, S., Baruah, P., Beavan, R., Birkin, M., Blainey, S., Byers, E., Chaudry, M., Curtis, T., Ebrahimy, R., Eyre, N., Hiteva, R., Jenkins, N., Jones, C., Kilsby, C., Leathard, A., Manning, L., Otto, A., Oughton, E., Powrie, W., Preston, J., Qadrdan, M., Thoung, C., Tyler, P., Watson, J., Watson, G. and Zuo, C. National infrastructure assessment: Analysis of options for infrastructure provision in Great Britain, Interim results. Environmental Change Institute, University of Oxford (2014). 
poor". The research reported in this paper has expanded the understanding what may be the right problems to address and suggests a future research strategy to explore further the problem space.

\section{THE NAVY YARD AND PHILADELPHIA REGION}

The Navy Yard in Philadelphia is a 1,200 acre facility that, until the early 1990s, was a U.S. Navy ship building facility, which began operation at its current location during the American Civil War ${ }^{10}$. The Navy Yard traces its origin to the first naval shipbuilding facility of the United States founded at the beginning of the country. In the early 1990s, the Base Realignment and Closure Commission recommended its closing. The U.S. Navy still has facilities at The Navy Yard, notably the Naval Ship Systems Engineering Station (NAVSEA) and Naval Inactive Ship Maintenance Facility. The Philadelphia Industrial Development Corporation (PIDC) manages the site for the City of Philadelphia. The Navy Yard serves as home to the Department of Energy, Consortium for Building Energy Innovation (CBEI). The research at CBEl served as a starting point for exploring the interdependencies of infrastructure systems in the larger region.

\section{SCENARIO PLANNING SCOPING MEETING AND SYSTEMS WORKSHOP}

On September 19, 2013, a half day scenario planning scoping meeting was held at the Navy Yard CBEI with a select group of infrastructure system planners and practitioners. The participants represented the regional transit organization, the national passenger rail service, the management company that operates the Navy Yard buildings and grounds, the regional planning commission, and a local chamber of commerce organization in addition to Penn State engineering faculty. One aim of the meeting was to build upon existing scenario analysis and planning work related to the region ${ }^{11,12,13,14,15,16,17}$.

Also participating in the scoping meeting were Dr. Paulien Herder, Dr. Theo Toonen, and Dr. Jeroen van den Hoven from TU-Delft, who are part of an EU-wide Next Generation Infrastructures project and Dr. Banning Garrett, one of the contributors to the United States National Intelligence Council's Global Trends 2030 report ${ }^{18}$. The main purpose of the scoping meeting was to identify problems, questions, and issues related to developing a next generation built environment-transportation infrastructure system focused on The Navy Yard and the Philadelphia region, but also to recognize the region's relationship to global trends and to learn from related infrastructure work in Europe. An expected outcome of this meeting was a preliminary, applied engineering systems research and education agenda for a follow-up workshop to be held in 2014 on interdependent infrastructure.

An overarching concern expressed at the September meeting was the fragmentation of the decision and policymaking processes of the different stakeholders that govern, operate, and invest in the infrastructure. Four main themes emerged from the September discussion: 1. vulnerability of aging infrastructure, 2. integration of emerging technology into existing infrastructure, 3. lifestyle and value changes influencing infrastructure demand and use, and 4. financial innovations needed to fund infrastructure re-development including workforce education. In listening to the participants' concerns, the use of computational models appeared as the next step beyond qualitative scenarios

\footnotetext{
9 Kleindorfer, P. R., Kunreuther, H. C. \& Schoemaker, P.J.H. Decision Sciences: An Integrated Perspective. Cambridge: Cambridge University Press (1993).

10 PIDC (Philadelphia Industrial Development Corporation http://www.pidcphila.com/ (2014).

11 Amtrak. The Amtrak Vision for the Northeast Corridor, (2012).

12 Delaware Valley Regional Planning Commission. Making the Land Use Connection: Regional What-If Scenario Analysis. September. Delaware Valley Regional Planning Commission (2008).

13 Delaware Valley Regional Planning Commission. Making the Land Use Connection: Regional What-If Scenario Analysis. September. Delaware Valley Regional Planning Commission (2008).

14 Delaware Valley Regional Planning Commission. Connections 2040: Plan for Greater Philadelphia. July. Delaware Valley Regional Planning Commission (2013).

15 Economy League of Philadelphia. 2026: Future Histories of Greater Philadelphia. Philadelphia, Pennsylvania: Economy League of Philadelphia (2011)

16 Fusco, B. The Future of Scenario Planning. Delaware Valley Regional Planning Commission. White Paper, March (2014).

17 Robert A. M. Stern Architects. The Navy Yard Master Plan Update (2013).

18 Burrows, M. Global Trends 2030: Alternative Worlds. Washington, DC: National Intelligence Council (2012).
} 
to gain a deeper understanding of the critical interdependencies among systems. These models should contribute to effective decision making for the management of risks and the evaluation of public-private investments to achieve resiliency, sustainability, competitiveness, security, and social acceptability.

A follow-up systems workshop was held April 3, 2014 with the goal to identify variables, parameters, constraints, and the data needed to model accurately the interdependencies of complex, adaptive socio-technical infrastructure systems. The workshop included a representative of the regional electric power transmission organization as well as participants from the Pennsylvania State Police responsible for critical infrastructure intelligence and protection, and Dr. Asta Zelenkauskaite from Drexel University. Dr. Kevin Stamber from Sandia National Laboratories presented on complex, adaptive systems of systems (CASoS) projects that the laboratory had conducted, some of which were already performed on "smart grids" for electricity distribution at the Navy Yard and national petroleum supply chain vulnerabilities ${ }^{19}$. Other participants included General James E. Cartwright, the $8^{\text {th }}$ Vice Chairman of the US Joint Chiefs of Staff, who led a discussion on the interactions among cyber and physical systems and the challenges that enterprises face integrating emerging technologies into a wide diversity of systems in an attempt to increase overall performance. Mr. Bob Prieto, Senior Vice President of Fluor and author of Strategic Program Management 20; Dr. Janet Barlow, Director of the Centre for Technologies for Sustainable Built Environments, University of Reading, UK.; and Dr. Marc Weiss, Chairman of Global Urban Development discussed different aspects of infrastructure independencies to provide, as in the September scoping meeting, a broader perspective to understand the infrastructure challenges of the Philadelphia region.

Three possible projects were suggested at the workshop and call for further investigation:

1. A need to assess new public transportation connections to areas of the region that are already experiencing renewal and growth, particularly University City - Navy Yard - 30 th Street Station.

2. A need to assess energy supply and demand at the Navy Yard and region to understand the implications of current and projected economic growth rates, which would include future energy capacity needs, options, and risks. A modeling project would also assess the implications of increased energy supply from natural gas for the development of new manufacturing and the competitiveness of unique regional assets, such as food refrigeration.

3. A need to assess the implications and risks of extremes in weather to existing and future infrastructure and model a strategy for infrastructure renewal and protection accounting for the lessons observed from super storm Sandy. Specifically, the modeling would identify the vulnerabilities and implications for cascading system failures among the built environment, energy systems, and transportation infrastructure and consider the linkages to other critical infrastructure such as water, food, communication, and public health.

Each of the three possible projects has economic, environmental stewardship, and security dimensions that interact. There are variables of aging infrastructure, emerging technologies, stakeholder-customer values and behavior changes, and alternative mechanisms for public-private financing among the systems as well as interdependencies that may not be entirely clear generating risks as well as opportunities. During the summer of 2014, we will be coordinating with Sandia National Laboratories on developing models to explore the three projects for further research. We have also begun to engage The Mayor of Philadelphia's Office of Sustainability to assess the implications and risks of extremes in weather to the Navy Yard and the Philadelphia region in relationship to the City's climate adaptation strategy.

\section{DISCUSSION AND FUTURE RESEARCH}

The Navy Yard project has begun to explore the systems of systems problem space related to the resiliency, security, sustainability, and competitiveness of the Philadelphia Metro Region and there are many fundamental questions to ask. What defines the resiliency, security, sustainability, and competitiveness of a region? How do different infrastructure sociotechnical systems contribute to resiliency, security, sustainability, and competitiveness? How is the resiliency, security, sustainability, and competitiveness of one region related to another? Although this project focuses on the Philadelphia Metro Region, we recognize that the Philadelphia Metro Region is an intrinsic part of the larger

19 Brown, T. J., R. J. Glass, R.J., Beyeler, W. E., Ames, A. L, Linebarger, J. M., \& Maffitt, S. L. Complex Adaptive System of Systems (CASoS) Engineering Applications Version 1.0. Sand Report 2011-8032. (October 2011).

20 Prieto, B. Strategic Program Management. McLean, Virginia: Construction Management Association of American (2008). 
U.S. mid-Atlantic corridor and that the knowledge generated will have broader practical implications for the larger region. Events external to the region, such as the widening of the Panama Canal will influence the region through increased commerce, will also need to be considered. This will require an enlarged collaborative research effort with multiple stakeholders of critical infrastructure that operate under different socio-technical constraints throughout the mid-Atlantic region.

Three general questions have guided the research. First, what are the challenges that systems practitioners face from their point of view? Second, what is the relationship between sociotechnical systems theory and practice generally with lessons specifically applied to this case? Third, how does sociotechnical systems theory inform systems practice and how may practice improve theory? These questions are asked to understand how infrastructure sociotechnical systems are interdependent, which is central to the evaluation of investment in a particular infrastructure project that may influence the performance of systems of systems across a range of expected outcomes, such as resiliency, competitiveness, sustainability, and social acceptability. Understanding the interdependencies of infrastructure is also essential to avoid cost and schedule overruns as well as canceled projects ${ }^{21,22,23}$.

The overarching concern of a fragmented regional policy and decision making process and the four theme areas of 1. vulnerability of aging infrastructure, 2. integration of emerging technology into existing infrastructure, 3 . lifestyle and value changes, and 4. financial innovations were identified as challenges through the scenario scoping meeting. Consequently, a main outcome of the follow-on systems workshop was the identification of three possible projects for further study that reflect the challenges expressed in the scoping meeting.

Since the April 2014 systems workshop, we have discussed the findings with our colleagues at Sandia National Laboratories and regional participants about how to proceed with a systems modeling activity. As of July 2014 we are evaluating which of the three possible research projects would yield the greatest expected benefits for the resources expended and that include the value of future real options for follow-on research and development ${ }^{24,25} 26$. Three related activities will also inform the modeling process. The first is the development of the South Eastern Pennsylvania Transportation Authority (SEPTA) strategic business plan. The second is the Delaware Valley Regional Planning Commission's September 2014 launch of a public participation website and meetings on the driving forces and game changers that may influence transportation in the region. The third is the Mayor's Office of Sustainability effort to develop a climate adaptation plan for infrastructure.

Our future research strategy is to leverage existing modeling efforts for energy, transportation, the built environment, and land-use planning, which includes a recently completely Sandia study on the implementation of smart grid technology at The Navy Yard, to evaluate future technology investments across a range of criteria. The metrics are to be determined. As part of the research, we are in the process of developing a high level sociotechnical systems influence diagram that will enable us to get a "bird's eye" so we can see in a general way the interdependencies of the social and technical systems related to the three possible projects.

We initiated this project with the idea of developing a "strategic conversation" through scenario planning among system practitioners and planners to identify challenges to regional systems and better understand how the systems functioned and depended upon one another ${ }^{26}$. The challenge of designing and evolving infrastructure systems is a "wicked" problem such that stakeholders need to engage in a "discipline of systematic thinking" to better understand which problems to address and to better understand the associated risks ${ }^{27}$. Engaging in "reasoned imagination is thus an important part of risk assessment because it implies, first, anticipating by systematic analysis scenarios that have not happened yet, and second, recognizing and communicating these unusual signals ${ }^{28}$.

Scenario and sociotechnical systems analysis can also make intelligible policy processes that are not necessary the

21 Flyvbjerg, B., Bruzelius, N. and Rothengatter, W. 2003. Megaprojects and Risk: An Anatomy of Ambition. Cambridge, United Kingdom: Cambridge University Press.

22 Merrow, E. W. Industrial Megaprojects. Hoboken, New Jersey: John Wiley \& Sons (2011).

23 Prieto, B. Personal Communication (2013).

24 Dixit, A. K. \& Pindyck, R. S. The Options Approach to Capital Investment. Harvard Business Review, (May-June): 105-115 (1995).

25 de Neufville, R. \& Scholtes, S. 2011. Flexibility in Engineering Design. Cambridge, MA: The MIT Press (2011).

26 Van der Heijden, K. Scenarios: The Art of the Strategic Conversation. 2nd edition. Chichester, England: John Wiley \& Sons (2005).

27 Buchanan, R. Wicked Problems in Design Thinking. Design Issues 8: 5-22 (1992).

28 Paté-Cornell, E. On "Black Swans" and "Perfect Storms": Risk Analysis and Management When Statistics Are Not Enough. Risk Anal. 32: 1823-1833 (2012). 
outcome of a well-ordered, "rational" decision process ${ }^{29}$. A better understanding of the policy making process is needed because, "we are attempting to build systems that are beyond our ability to intellectually manage; increased complexity of all types makes it difficult for designers to consider all the potential systems states or for operators to handle all normal and abnormal situations and disturbances safely and effectively. In fact, complexity can be defined as intellectually unmanageability"30. How one understands and communicates what one knows and does not know about complex sociotechnical systems of system problems is also an ethical issue. According to Churchman "whoever attempts to tame a part of a wicked problem, but not the whole, is morally wrong." "Look, I've not tamed the whole problem, just the growl; the beast is still as wicked as ever ${ }^{31}$."

\section{ACKNOWLEDGEMENTS}

We gratefully acknowledge the support of the Larson Institute and the Strategic and Global Security Program at Penn State and the financial support of Alcoa. We also acknowledge the comments of two anonymous reviewers.

29 Zahariadis, N. The Multiple Streams Framework: Structure, Limitations, Prospects. Chapter 3 in Theories of the Policy Process, edited by P. A. Sabatier. Boulder, Colorado: Westview Press (2007).

30 Leveson, N. G. Engineering a Safer World: Systems Thinking Applied to Safety. Cambridge, Massachusetts: The MIT Press (2011).

31 Churchman, C. W. Wicked Problems. Management Sci. 14:B-141-142 (1967). 